\title{
The Definition and Measurement of Small Military Unit Team Functions
}

\author{
Samuel Shiflett, Ellen J. Eisner, \\ Shelly J. Price, and F. Mark Schemmer \\ Advanced Research Resources Organization
}

ARI Field Unit at Fort Benning, Georgia

Training Research Laboratory

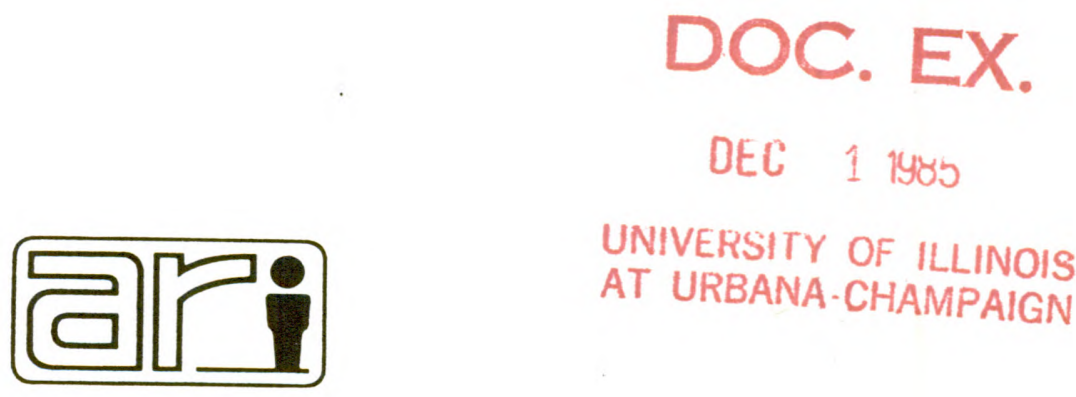

U. S. Army

Research Institute for the Behavioral and Social Sciences

May 1985

Approved for public release; distribution unlimited. 